\section{COVID 19}

\author{
Suroso $^{1}$, Delia Shukmalla ${ }^{2}$ \\ suroso@ubpkarawang.ac.id
}

mn17.deliashukmalla@mhs.ubpkarawang.ac.id

\begin{abstract}
ABSTRAK
Koordinasi diperlukan untuk mengkomunikasikan kebijakan-kebijakan atau programprogram untuk pembangunan desa yang sudah ditentukan dalam RKPdes. Pembangunan merupakan upaya untuk meningkatkan taraf hidup masyarakat yang berkualitas dan bermartabat. Pembangunan diperluka untuk mengisi kekosongan pasca kemerdekaan.

Ketercapaian pembangunan tidak lepas dari peran pemerintah desa sebagai penggerak pembangunan tersebut. Penggunaan sumber daya yang efektif dan efesien merupakan kunci utama kesuksesan pembangunan. Dalam mewujudkan hal tersebut diperlukan suatu koordinasi antar anggota masyarakat dengan pemerintah desa dalam wadah rapat mingguan (minggon).

Metode penelitian ini menggunakan metode deskriptif dengan memberikan penjelasan atas suatu fenomena atau mendeskripsikan karakteristik suatu objek. Sedangkan analisis yang dipergunakan analisis deskriptif kualitatif dengan langkah-langkah yaitu; (1) mengumpulkan data dan informasi yang dibutuhkan tentang objek; (2) mengidentifikasi masalah serta menganalisis secara mendalam; (3) membuat rancangan bangun sistem sesuai kebutuha kondisi lapangan; (d) memberikan rekomendasi dan implementasi perancangan yang cocok.

Minggon merupakan instrumen penting bagi Desa, tujuan diadakannya rapat setiap minggu untuk memfollow up program kerja yang telah dicanankan dalam RPJMDes, selain itu Minggon membantu menyelesaikan masalah dengan cara musyawarah antara perangkat Desa dengan masyarakat langsung untuk mencapai mufakat. Hasil Minggon setiap mingguan di tulis dalam Notulen sebagai dokumen Desa, selain itu sebagai acuan untuk menyelesaikan program yang sedang berjalan.
\end{abstract}

Key: Koordinasi, Pembangunan.

ABSTRACT

Coordination is needed to communicate policies or programs for village development that have been determined in the RKPdes. Development is an effort to improve the quality of life of the people with quality and dignity. Development is needed to fill the post-independence void.

The achievement of development cannot be separated from the role of the village government as the driving force for this development. Effective and efficient use of resources is the main key to successful development. In realizing this, a coordination between community members and the village government is needed in a weekly meeting forum (weekday).

This research method uses descriptive methods by providing an explanation of a phenomenon or describing the characteristics of an object. While the analysis used qualitative descriptive analysis with the steps, namely; (1) collect required data and information about objects; (2) identify problems and analyze in depth; (3) designing system build according to kebutuha field conditions; (d) provide recommendations and implement suitable designs.

Minggon is an important instrument for the village, the aim of which is to hold meetings every week to follow up on the work programs that have been announced in the RPJMDes, besides that 
Minggon helps solve problems by means of deliberation between village officials and the community directly to reach consensus. The results of the weekly week Minggon are written in the Minutes as Village documents, in addition to that as a reference for completing the ongoing program.

Key: Coordination, Development.

\section{PENDAHULUAN}

Desa Lemahsubur merupakan wilayah pemekaran dari Desa Lemahmakmur, Seiring dengan perkembangan waktu, jumlah penduduk serta kebutuhan akan pelayanan masyarakat maka tokoh masyarakat memperjuangkan pembentukan desa melalui proses pemekaran desa. Desa Lemahsubur diresmikan pada 12 Agustus 1982. Desa Lemahsubur merupakan salah satu Desa yang berada di Kecamatan Tempuran, Kabupaten Karawang. Penduduk Desa Lemahsubur mayoritas bergerak di bidang pertanian. Tanaman yang paling banyak ditanam di desa ini adalah padi, yakni sebanyak 60\% dari lahan desa. Pembagian wilayah Desa Lemahsubur terbagi dalam 4 (empat) Dusun yaitu Dusun Pondokbales, Dusun Pasirmalang, Dusun Suagar dan Dusun Padatimulya. Oleh karena itu pembangunan Desa mempunyai peran yang sangat penting dalam pembangunan nasional dan daerah, di dalamnya terkandung unsur pemerataan pembangunan dan hasil - hasilnya, termasuk pemenuhan kebutuhan masyarakat yang bermukim di pedesaan untuk meningkatkan kesejahteraan.

Salah satu elemen mendasar dalam penyelenggaraan pembangunan desa adalah ketersediaan RPJMDes dan RKPDes, karena kedua dokumen tersebut merupakan arah kebijakan pembangunan jangka menengah dan jangka pendek desa. Oleh karena itu dibuatlah sebuah rapat mingguan atau musyawarah Mingguan, untuk membantu memantau pembangunan desa. Minggon merupakan sebuah rapat mingguan Desa yang dilaksanakan setiap minggu pada hari Rabu. Peserta rapat dihadiri oleh aparat Desa dan perwakilan masyarakat. Minggon merupakan suatu koordinasi atau sebuah fasilitator dengan tujuan memfollow up program kerja Desa ( sesuai dengan RPJMDes) serta menyelesaikan berbagai kendala yang terjadi.

\section{TINJAUAN PUSTAKA}

Koordinasi merupakan cara utama bagi organisasi untuk proses percepatan pencapaiaan tujuan. Koordinasi digunakan pada semua kegiatan organisasi. Mulai dari tingkat perumusan kebijaksanaan sampai pada tingkat pelaksanaan program yang disusun (Manopo dkk, 2017).

Koordinasi merupakan suatu usaha, kerjasama, kegiatan-kegiatan, dan kesepakatan bersama 
secara teratur serasi, selaras, seimbang dan serempak untuk mencapai suatu tujuan dan mencegah terjadinya konflik, kekacauan, percekcokan, kekosongan pekerjaan dan sebagainya dalam suatu organisasi. (Lumi dkk, 2017)

Berdasarkan tujuan koordinasi Mali dkk (2019) menyimpulkan bahwa untuk memaksimalkan proses penyusunan (rencana kerja pegawai desa) RKPDes Desa. Selain itu koordinasi juga dilakukan untuk memaksimalkan pelayanan masyarakat dan memaksimalkan sarana dan prasana yang tersedia untuk mencapai tujuanbersama. Mali dkk (2019) juga mengatakan bahwa koordinasi memiliki prinisp yang mengedepankan suatu hubungan kerjasama yang baik, perencanaan yang baik, serta tujuan yang sama dalam merencanakan program kegiatan dalam RKPDes.

Koordinasi dapat dilakukan dengan beberapa cara, diantaranya adalah: (1) mengadakan pertemuan formal antara para pejabat dan unit, (2) mengadakan pertemuan informal, (3) membuat edaran berantai kepada para pejabat yang diperlukan, (4) mengangkat koordinator, (5) membuat buku pedoman organisasi, buku pedoman tata kerja dan buku pedoman kumpulan peraturan, (6) komunikasi dengan berbagai cara yang lain.

Manopo dkk (2017) Pembangunan desa adalah suatu program untuk meningkatkan taraf hidup dan kesejahteraan rakyat pedesaan lahir dan batin yang merupakan suatu gerakan untuk kemajuan dalam mewujudkan masyarakat pancasila. Sedangkan menurut Lumi dkk (2017) Pembangunan pada dasarnya sebagai upaya yang terencana dan terprogram secara terus menerus oleh satu Negara untuk menciptakan masyarakat yang lebih baik. Dewasa ini bangsa Indonesia sedang melakukan pekerjaan yang sangat besar yaitu mengisi kemerdekaan dengan melaksanakan pembangunan.

Menurut Hasil penelitian Lumi dkk (2017) koordinasi pemerintah desa dalam pelaksanaan pembangunan di Desa meliputi:

1. Komunikasi Pemerintah Desa dan Masyarakat dalam Pelaksanaan Pembangunan maksudnya Komunikasi antara pemerintah desa serta masyarakat desa terselenggara dengan baik, komunikasi lebih mengarah kepada penyampaianpenyampaian informasi kepada masyarakat beserta masukan-masukan langsung dari masyarakat tentang pembangunan.

2. Pentingnya Koordinasi Pemerintah dan Masyarakat, maksudnya Dalam pelaksanaan pembangunan partisipasi dari masyarakat sangat antusias. Partisipasi masyarakat dalam pembangunan sudah cukup aktif baik dalam baik partisipasi langsung maupun tidak langsung.

3. Kompetensi Masyarakat dalam Pembangunan, maksudnya Dalam penyelenggaraan pemerintahan khususnya dalam pembangunan pemerintah desa selalu berkoordinasi terlebih dahulu bersama aparat desa dan badan permusyawaratan desa, walaupun masih ada 
masyarakat yang tidak paham tentang koordinasi yang dilakukan oleh pemerintah desa. akan tetapi, koordinasi pemerintah desa dalam setiap pelaksanaannya selalu melalui perencanaan yang terstruktur dan lewat komunikasi yang baik.

4. Kontinuitas Perencanaan Pemerintah Desa dalam Pelaksanaan Pembangunan, maksudnya Perencanaan pembangunan selalu dimusyawarahkan terlebih dahulu lewat musrembangdes (Desa), sehingga keberhasilan pembangunan selalu berkelanjutan dengan arah tujuan yang diinginkan bersama.

\section{METODE}

Penulisan artikel ini diperoleh dari hasil KKN yang dilakukan secara online dan penelitian secara langsung dilapangan dengan mengikuti protokol Covid-19 yang kemudian disusun dan diolah secara sistematis. Penelitian ini menggunakan metode deskriptif dimana pengumpulan informasi yang didapat bersumber dari hasil observasi dan wawancara dengan pihak terkait secara online (menggunakan media WA dan Email) dan langsung dengan tetap memperhatikan protokol covid-19.

Analisis yang dipergunakan analisis deskriptif kualitatif dengan langkah-langkah yaitu; (1) mengumpulkan data dan informasi yang dibutuhkan tentang objek; (2) mengidentifikasi masalahserta menganalisis secara mendalam; (3) membuat rancangan bangun sistem sesuai kebutuha kondisi lapangan; (d) memberikan rekomendasi dan implementasi perancangan yang cocok. 


\section{HASIL DAN PEMBAHASAN}

Salah satu elemen mendasar dalam penyelenggaraan pembangunan desa adalah ketersediaan RPJMDes dan RKPDes, karena kedua dokumen tersebut merupakan arah kebijakan pembangunan jangka menengah dan jangka pendek desa. Oleh karena itu dibuatlah sebuah rapat mingguan atau musyawarah Mingguan, untuk membantu memantau pembangunan desa. Minggon desa Lemahsubur dilaksanakan setiap minggu pada hari Rabu. Peserta rapat dihadiri oleh aparat Desa dan perwakilan masyarakat. Minggon merupakan sebuah fasilitator dengan tujuan memfollow up program kerja Desa ( sesuai dengan RPJMDes) serta menyelesaikan berbagai kendala yang terjadi.

Hasil Minggon setiap mingguan di tulis dalam Notulen sebagai dokumen Desa, selain itu sebagai acuan untuk menyelesaikan program yang sedang berjalan.. Dengan diadakannya Minggon setiap hari Rabu masyarakat bisa mengetahui bagaimana program Desa berjalan, dan dengan dihadirkannya masyarakat dalam Minggon dapat memudahkan menyelesaikan masalah yang terjadi. Dengan bertukar pendapat mencari solusi bersama untuk pembangunan desa dan kesejahteraan bersama.

Dalam masa Pandemi seperti sekarang ini hampir semua bidang terkena dampak dari Pandemi tersebut. Terutama pada bidang ekonomi dan pendidikan. Berbagai bantuan diberikan oleh pemerintahan Pusat maupun daerah untuk membantu masyarakat. Diantaranya yaitu JPS (Kabupaten), BST (Pusat) bantuan yang diberikan kepada masyarakat terdampak Covid-19 dan Bantuan Langsung Tunai (BLT) untuk masyarakat tidak mampu. Berikut dokumen Nama nama masyarakat yang diberi bantuan :

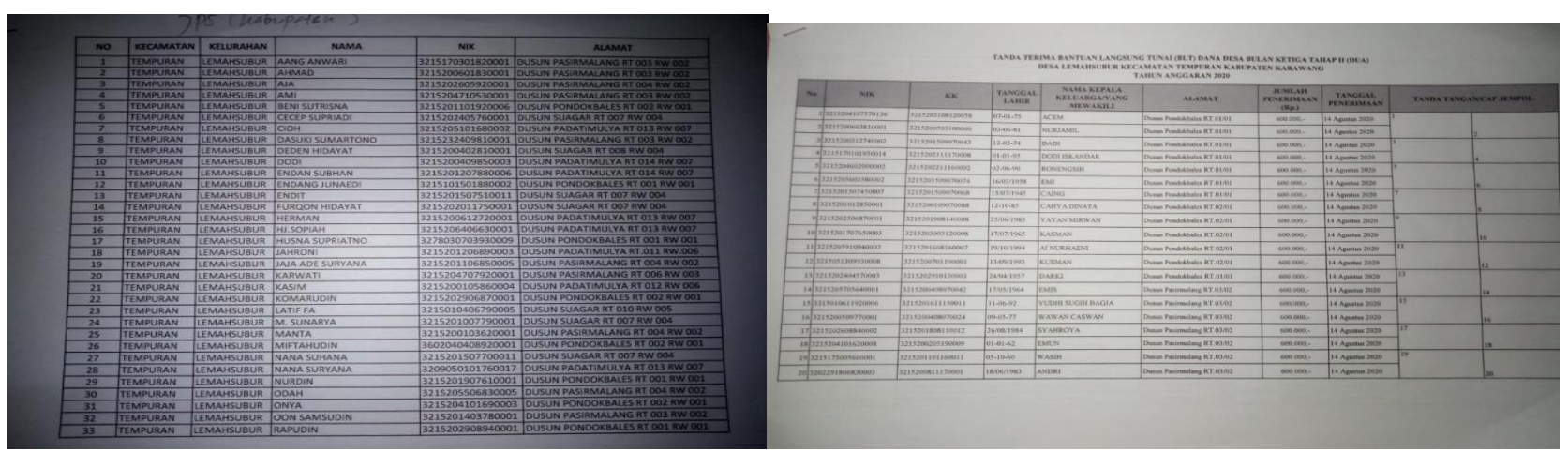

Gambar 1. Daftar Nama Penerima Bantuan JPS dan Penerima Bantual BLT

Sumber : Dokumen Desa Lemahsubur 2020 
Beberapa Bahasan hasil rapat Minggon, diantaranya :

1. Telah melaksanakan kerja bakti pasa hari Minggu tanggal 16 Agustus

2. Telah Melaksanakan peringatan Hut Desa

3. Perintah untuk selalu menggunakan masker

4. Badan Pusat Statistik tahun 2020 1-30 September tentang sensus penduduk

5. Anjuran dari PMI untuk mendonor darah (pendonor harus memenuhi syarat)

6. Pendataan Pajak kendaraan mobil dan motor bagi yang belum terdaftar bayar pajak

7. Musrembang Desa ( Musyawarah RKPDes tahun 2020, Dana Desa sebessar Rp 975.000.000 thn 2020)

8. Pelebaran Jalan ujung Kampung

9. Pembuatan Jembatan Kondang sari

\section{Kendala}

Beberapa kendala koordinasi dalam minggon yang terjadi di desa Lemahsubur diantaranya :

1. Sulitnya Mengumpulkan semua peserta Minggon untuk menghadiri setiap pertemuan.

2. Notulen yang tidak semua dicatat sehingga tidak tercatat dalam buku Notulen.

3. Masalah dalam apek pembagian bantuan, seperti masyarakat yang sulit memberikan persyaratan pada pihak Desa, keterlambatan memberikan dokumen, kesalahan pendataan.

4. Kurangnya sarana penunjung Pendidikan, seperti perpustakaan desa.

\section{ANALISIS PENANGANAN MASALAH}

Analisis penangana masalah untuk mengatasi masalah tersebut diantaranya yaitu :

1. Perlunya kesadaran dari semua pihak dalam menghadiri rapat, untuk mempermudah memfollow up program kerja dan meninjau masalah yang terjadi agar terlaksananya pembanguanan desa.

2. Perlunya Notulen hasil rapat setiap Minggu, karena Notulen merupakan bukti fisik sehingga dapat menjadi acuan dalam melaksanakan PR yang sedang dikerjakan atau yang belum dikerjakan.

3. Aparat Desa seperti Wakil Dusun melakukan pendekatan lebih kepada masyarakat, terutama pada masyarakat awam yang kurang faham. Agar syarat untuk mendapatkan bantuan lebih mudah dikumpulkan

4. Pemerintahan Desa memberikan fasilitas penunjungan pendidikan, seperti mendirikan sebuah taman bacaan untuk para Siswa maupun umum. 


\section{KESIMPULAN}

Berdasarkan pembahasan yang telah dijelaskan maka kesimpulan yang didapat yaitu, Minggon merupakan instrumen penting bagi Desa, tujuan diadakannya rapat setiap minggu untuk memfollow up program kerja yang telah dicanankan dalam RPJMDes, selain itu Minggon membantu menyelesaikan masalah dengan cara musyawarah antara perangkat Desa dengan masyarakat langsung untuk mencapai mufakat. Hasil Minggon setiap mingguan di tulis dalam Notulen sebagai dokumen Desa, selain itu sebagai acuan untuk menyelesaikan program yang sedang berjalan. Dengan diadakannya Minggon setiap hari Rabu masyarakat bisa mengetahui bagaimana program Desa berjalan, dan dengan dihadirkannya masyarakat dalam Minggon dapat memudahkan menyelesaikan masalah yang terjadi. Dengan bertukar pendapat mencari solusi bersama untuk pembangunan desa dan kesejahteraan bersama. 


\section{DAFTAR PUSTAKA}

Lumi, Bill A. Novie R. Pioh dan Alfon Kimbal. 2017. KOORDINASI PEMERINTAH DESA DALAM PELAKSANAAN PEMBANGUNAN (Studi di Desa Sinsingon Barat Kecamatan Passi Timur Kabupaten Bolaang Mongondow). Universitas Sam Ratulangi: Jurnal Ilmu Pemerintah. Vol. 1. No. 1.

Mali, Yoakim Antonius , Nikolaus Uskono, dan Wilfridus Taus. 2019. KOORDINASI PEMERINTAH DESA DALAM PENYUSUNAN RENCANA KERJA

PEMERINTAH DESA (RKPDes) (Penelitian di Desa Manumutin Silole Kecamatan Sasitamean Kabupaten Malaka). Universitas Timor: Jurnal Administrasi Negara. Vol 1 No. 1

Manoppo, Isye Regina Altje. Michael Mantiri dan Sarah Sambiran. 2017. FUNGSI KOORDINASI PEMERINTAH DESA DALAM PELAKSANAAN PEMBANGUNAN (Studi di Desa Buise Kecamatan Siau Timur Kabupaten Sitaro). Universitas Sam Ratulangi: Jurnal Ilmu Pemerintah. Vol. 2. No. 2. 